\title{
Mood Inference Machine: Framework to Infer Affective Phenomena in ROODA Virtual Learning Environment
}

\author{
http://dx.doi.org/10.3991/ijac.v5i1.1740 \\ Magalí Teresinha Longhi, Patricia Alejandra Behar, and Magda Bercht \\ Federal University of Rio Grande do Sul/PGIE, Porto Alegre, Brazil
}

\begin{abstract}
This article presents a mechanism to infer mood states, aiming to provide virtual learning environments (VLE) with a tool able to recognize the student's motivation. The inference model has as its parameters personality traits, motivational factors obtained through behavioral standards and the affective subjectivity identified in texts made available in the communication functionalities of the VLE. In the inference machine, such variables are treated under probability reasoning, more precisely by bayesian networks.
\end{abstract}

Index Terms-Affective modeling, Bayesian networks, virtual learning environments.

\section{INTRODUCTION}

This article presents studies and results obtained in the incorporation of a framework conceived to infer mood states in a virtual learning environment (VLE). It is a study carried out in the scope of a wider investigation, undertaken by the Center of Technology Applied to Education (NUTED) along with the Group of Affective Computing Applied to Education (GCAE) from the Federal University of Rio Grande do Sul (UFRGS).

In this context, the research aims to examine how the affective dimension is expressed in a virtual context and, mainly, how it is manifested in the learning process along the interactions that take place in such environments.

Concerning the study, the hypothesis is that it is possible to recognize the mood states of a student in a VLE through a computing model. Such model is used so as to establish correlations between selected variables, such as personality traits, motivational factors, and affective subjectivity identified in texts made available in a virtual environment. The platform used was the ROODA VLE from UFRGS.

In a VLE, the subjects participating do not interact only with the technological infrastructure - graphics interface, synchronous/asynchronous communication tools and other functionalities. There is also, in such environments, the formation of several relationships, such as cognitive, affective, symbolic and socio-behavioral [1]. As a result, a VLE has potentialities that go beyond a mere content repository, organization of a discipline/course or contact among participants. It is possible to see a new approach to VLE, whose technological functionalities represent important sources for the inference of affective aspects.

Related to this new approach, Affective Computing [2] congregates techniques of Artificial Intelligence, Software Engineering, and Computer Engineering, focusing on af- fectivity and its role in human experience. However, it is still difficult to model emotions in computing systems, mainly because of three factors, according to Bercht [3]: the strong influence of Cartesian thought, which sees reason as opposed to emotion; the lack of definition of the terms associated with affectivity; and, finally, in terms of computing, the use of logic and formalisms aiming exclusively to the representation of knowledge.

The dichotomic view between cognition and affectivity has remained up to very recently since Plato distinguished the body from the "soul" structuring it as divided into cognition, emotion, and volition. Although Piaget [4] and Vygotsky [5] had demonstrated interest in the relation between cognition and the affective aspects, only after the 1980's affectivity in cognitive activities began to be emphasized, as it is verified in the theories of Zajonc [6] and Lazarus [7]. Later, the researches of neuroscientists such as Damásio [8] and Le Doux [9] presented significant evidence of the relationships between cognition and affectivity.

Concerning the definition of the terms related to affectivity, such as emotion, mood state, motivation, feeling, etc., are approached by several psychological theories and, even within their scope, according to different guidelines. For this reason, the distinct ways to define the various affective phenomena raise doubts regarding their differentiation. Scherer [10] has formulated criteria to distinguish them (importance of the event, type of appraisal, synchronization with the several organic subsystems, impact on the behavior, intensity, and duration). It is based on such criteria that, for the purpose of this study, the terms emotion and mood states will be defined, mainly the last one, which is particularly relevant to the objectives of this investigation.

Although emotion in common sense is taken as a synonym for affectivity and, oftentimes, it is confounded with feeling, it consists of a short affective state, with high intensity and with synchronized response to an event. An emotion can be classified as primary (basic or utilitarian) or secondary (or social). Primary emotions (fear, anger, sadness, happiness, surprise, despise and disgust) serve to guarantee survival, and were widely discussed by Ekman [11]. On the other hand, secondary emotions (arrogance, preoccupation, restlessness, sorrow/grief, enthusiasm, etc.) are acquired or learned from primary emotions as daily situations are faced as well as their developments.

In their turn, mood states represent a type of background emotion [8], with diffuse profile, of low intensity 
and duration. These states, it is worth noticing, can be triggered both by primary and secondary emotions [12].

Besides the factors discussed above, the difficulty in modeling affective phenomena in computing systems resides in the use of models created sob the Cartesian scientific method. These formal models represent cognitive mechanisms and they are examined according to the reductionist vision (the complex world must be divided into simpler parts). However, in some cases they can deal with complete and immutable domains and in others with uncertain reasoning domains.

Fellous, Armony and Le Doux [13] state that the techniques of Artificial Intelligence can be used to model cognitive processes (appraisals), even though each of them implies theoretical difficulties. Thus, when modeling affective phenomena, it is necessary to evaluate which is the most adequate model to represent knowledge, and also to identify the technologies that support it [14]. It is certain, however, that there are no models that are perfect to and able to identify the affective states. At times, mixing models might lead to better results than being restricted to a single model [2].

In this context, this article presents studies and the evaluation of results obtained in the application of a Bayesian Network (BN) with the aim of inferring the mood states. Such investigation was conducted based on undergraduate disciplines, which were supported by ROODA VLE. In the next section, studies related to the inference methods based on BNs are compiled. In section 3 , the student's affective model is presented and in section 4 the mapping of the mood states. Section 5 deals with ROODA, the environment of application. Section 6 shows the inference machine proposed and 7 the experiment and the results found. Finally, some considerations about the research performed are made.

\section{RELATED STUDIES}

Investigations about the recognition of emotions in a virtual environment and their modeling from BN are presented in $[15,16,17,18,19]$. Studies that involve personified and conversational agents became well-known. Based on information about the facial expressions, they infer emotion $[15,16]$ and mood states [16] of the user so as to generate adequate behaviors to interact with the user.

Other authors suggest the use of $\mathrm{BN}$ in computing agents conceived in order to infer students' emotions in collaborative games [17, 18] and in specialist systems [19]. The social agent proposed by Boff [19] takes into consideration the individual characteristics of the student, such as performance, social profile, acceptance (on the part of a classmate), affective state, personality traits, in order to identify the student's profile in the proposition of work groups. Conati's model [17] evaluates emotional states from a monitoring of student's interactions in an educational game considering the objectives and preferences (body expressivity is also evidence). A similar approach was adopted by Pantarolo [18]. His studies are based on a collaborative game. It infers the student's emotions in relation to himself/herself and to the other colleagues.

Under the strong influence of studies [17, 18, 19], the affective model defined for the purpose of this investigation is supported by a semantic network. The model aims

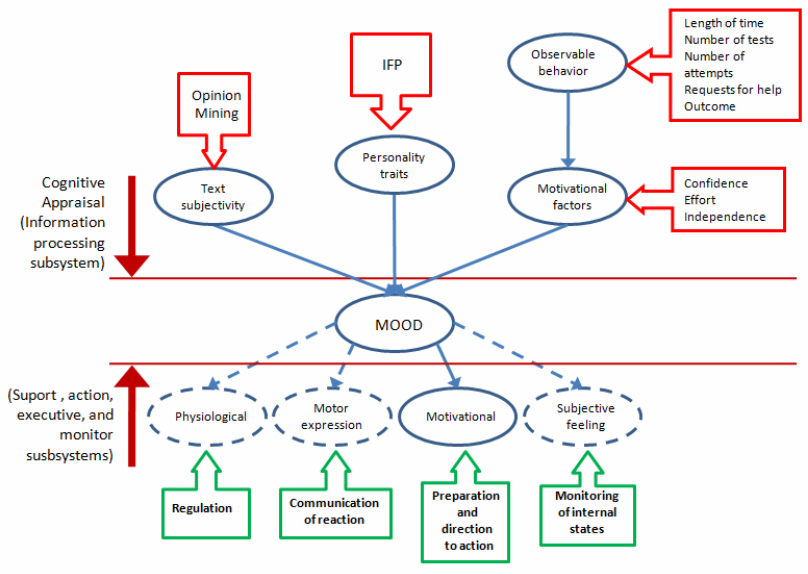

Figure 1. Classes of variables and relations of the affective model

to serve as a means for cognitive evaluation of the mood states in a VLE.

\section{STUDENT's AfFECTIVE MODEL}

The proposal of student's affective model, represented by the semantic network illustrated in Fig. 1, is inspired by Scherer's model [10].

In our model, the affective subjectivity in a text is considered as one of the explanatory variables of the student's mood state. It involves a unilateral judgment [20], which is consolidated as the student records the preoccupations, successes, and motivations in the texts made available in the communication functionalities of the VLE.

Affective subjectivity is inferred through the framework AWM (Affective Word Mining) [21], whose objective is to identify and to classify the words that have affective connotation present in a text. For this purpose, the mining process extracts the affective lexemes, which are submitted to a classification. The classification process consists of verifying in which position of the Roda dos Estados Afetivos - REA ("Emotion Wheel") each lexeme is inserted (the mapping of the mood states in REA is presented in the next section).

Observable behavior is understood as a systematic set of actions adopted by the student in the VLE. This way, the behavioral patterns indicate the motivational degree in the environment. We used the Bercht model [22] that was inspired in del Soldato and du Boulay [23] factors: Confidence, Effort, and Independence. These factors are considered as a marker of the mood states and each one is identified from the variables such as: number of accesses to the functionalities of ROODA, number of contributions to forums, frequency of participation, manner/mode of interaction with the participants, help and time of permanence in the session. The motivational degree of each factor is inferred by the framework BFC (Behavioral Factor Calculation) described in [24].

Personality traits constitute patterns through which the subject perceives reality and explain how the subject establishes social connections. They are usually determined by models characterized as factors or dimensions, which denote the specificity of an individual.

These dimensions are obtained through the application of psychometric tests. In this study, the instrument IFP Inventário Fatorial de Personalidade ("Personality Factor Inventory”) [25] was used, being applied and analyzed by 
a psychologist. The choice of the IFP is justified by the fact that it represents an instrument adapted to the Brazilian reality, reliable, and of verbal nature, which is more consistent with the purpose of this research. For this investigation, nine dimensions were selected: assistance, dominance, denegation, performance, aggression, order, persistence, change, and autonomy.

The three variables (personality traits, motivational factors, and affective subjectivity in a text) integrate the subsystem of information processing or cognitive appraisal [10] to determine the corresponding mood state. The other subsystems of Scherer's model that deal with physiological regulation, body dramatization, preparation for action to be taken and monitoring of subjective sentiment are not being contemplated in this study.

\section{MAPPING OF THE MOOD STATES}

Scherer and Tran [26, 27] described the impact of some affective phenomena on the learning process, especially on organizations in order to indicate which of them would influence on decision taking processes. The authors identified four classes of emotions: approach, achievement, resignation, and antagonistic.

The emotions, classified into affective families, are positioned in a space of representation according to what is presented in Fig. 2. This space, denominated REA in our research, is based on Trans's work [27]. Affective families in the REA constitute tags for a group of emotions. The position of the families in each quadrant of the REA is based on empirical justifications and on an extensive theoretical study conducted by Scherer [10] and Tran [27].

In this study, two classes of mood states are considered: being interested and being satisfied. Each class, in its turn, is divided into two subclasses based on the positive and negative valence: interested, uninterested, satisfied, and dissatisfied.

\section{A. Being Interested}

The term interested, in its figurative sense, designates the participation of the subjective in the acts of perception, representation, and thought [20] (on something or someone). It is the mood state that drives (or not) toward the pursued objectives. It can be identified in both the negative and the positive senses.

In the educational context, being interested evidences that the student, somehow, demonstrates surprise, interest, hope and/or relief to face the challenges of learning, which lead to collaboration and cooperation. These emotional families are associated with positive valence and low control over the events causing the affective state and their unfolding. That is, as the content is presented, the student shows willingness to trust even if the student holds little control over the learning experiences. It is said in this case that the mood state is future-oriented. It is composed of approach emotions, which imbue the student with positive encouragement to explore, develop and continue learning.

It is possible, however, that such approach emotions take negative connotation: being too quiet (relief) can induce a student to withdraw; being very hopeful can take one to the disengagement and practicing inappropriate actions; being too interested may distract someone; being overly surprised might originate confusing ideas or leave one paralyzed, inert or indifferent to learning.

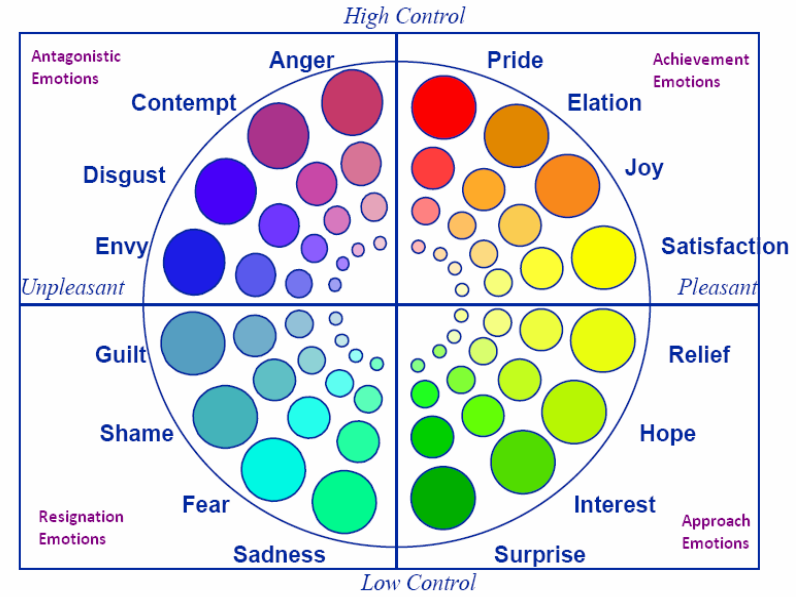

Figure 2. Emotions wheel from Tran [27, p. 66]

The mood state uninterested suggests that the student demonstrates (or represses the manifestation of) sadness, fear, shame and/or guilt for not being able to follow the contents. These affective families are characterized by a negative valence, low control over the events and their possible consequences as well as tendency to submission or renunciation. They are composed of resignation emotions, that is, those that can, at the limit, lead the student to quitting. Nevertheless, they might have positive implications so as to allow a recovery time to rethink attitudes, readapting to new conditions or avoiding problems.

\section{B. Being Satisfied}

The term satisfaction denotes the pleasure arising from the realization of what is expected, of what is wanted. In a positive sense, the mood state satisfied indicates that the student shows, in some way, satisfaction, joy, elation and/or pride in completing a task.

These affective families include positive valence and significant control over the events and their consequences, providing improved self-esteem and well-being. They are composed by achievement emotions, that is, those which establish an objective to be achieved and celebration of success.

When such emotions are overflowing, there may be adverse implications. In fact, a very proud student may provoke envy and hostility (needing, then, to deal with conflicts). One must consider that too much happiness or excitement can lead to a decline in productivity as well as high satisfaction might discourage the exploration of new alternatives.

With regard to the inference of the dissatisfied mood state, usually the student expresses, or tries not to show, anger, contempt, disgust and/or envy. These affective families, which are attributed negative valence and high control over the events and their consequences, reveal, especially aggressiveness. They are composed of antagonistic emotions, from which the student may encourage retaliation or revenge intentions.

On the other hand, they may have desirable implications, such as keeping the group together to achieve the goals and the ability to counter the injustices or overcome obstacles. Envy, in its positive sense, provokes admiration for the examples of peers and teachers, suggesting that they should follow the same path. Disgust may indicate that it is time to change positions, attitudes or behaviors. 
Contempt contributes to rethinking social norms; and a little bit of anger increases the confidence in some situations, such as in case of reacting to aggression.

\section{ROODA VLE}

The ROODA (Rede cOOperativa De Aprendizagem), institutionalized by UFRGS in 2005, is a VLE developed with its basis on constructivist principles [1], having implicit the interactionist conception from Piaget. The available functionalities in the ROODA might be grouped into classes: general resources, activity monitoring, publication of materials and communication.

The group of functionalities that includes general resources lets you view and change registration information, customize the user interface, record deadlines in the discipline, check the history of accesses to the functionalities and access the Help item. The functionalities of activity monitoring are responsible for making available class and study contents, exercises, and the participation in surveys. The resources of publication of materials allow the disclosure of personal and group material with the possibility of limiting the display of the content published. Finally, the tools of synchronous and asynchronous communication integrate the group of functionalities of communication. These enable virtual meetings and meeting spaces, supporting the movement of talks, discussions and coordination during the course.

The inference machine of the mood states is coupled with the ROODA VLE through the functionality ROODAafeto, developed by the NUTED/UFRGS. The new functionality integrates the class general resources of the ROODA VLE.

\section{PROBABILITY REASONING}

Bayesian Network (BN) is a computing abstraction chosen to support the semantic network described in section 3. Such choice is based on that it represents an adequate technology as it considers the aspects of uncertainty inherent to the affective dimension and also because it deals with the dynamic aspects.

It is understood that uniting personality traits to the affective subjectivity recognized in texts, as well as motivational factors obtained from behavioral patterns, supplies conditions to infer the student's mood status in a discipline/group developed (in part or as a whole) through a VLE. Affective subjectivity in texts recorded in the synchronous/asynchronous communication tools is considered to attribute higher or lower weight in the inference, and also constitute spontaneous manifestation. The student's affective model is applied on a BN so as to obtain statistical inferences, considering the probabilities associated with the events observed.

The BN is a type of semantic network represented by an acyclic directed graph, in which each node possesses probability information [28]. The nodes represent random variables (discreet or continuous) of the problem with measures of uncertainty associated. The links between nodes are made by arches that define the relations. The arcs identify the logical precedence or causal influence between variables connected. This precedence, or influence, determines the distribution of conditional probability, that is, a quantification of the effect of the father nodes upon the children nodes.
The BN can be analyzed from two perspectives: qualitative, as the graphic model represents the dependence between nodes, and quantitative by means of conditional probability tables (CPT). Thus, the reasons that justify the option for a BN in this work are: 1) the BN can express assertions of independence in visual form and, for this reason, it is possible to have a semantic perception of the problem, 2) the $\mathrm{BN}$ is suitable to represent and reason with uncertainty, with imprecision and probabilities, important characteristics that involve the treatment of affective aspects, 3) the BN represents and stores a joint distribution in a reduced way, exploring the sparsity of the relationship among the variables, and 4) the $\mathrm{BN}$ makes the inference process efficient from the computational point of view, although the probability distribution might grow exponentially.

The BN, designed in the NETICA software and presented in two parts in Fig. 3, represents the relations of the variables seen in Fig. 1. The variable Predominância-FP serves as a connection between the two networks. Once the topology of the network was specified, the CPT of each node was defined. Initially, a priori values are attributed to the probability of the independent variables (or nodes). The values are updated as the inference machine receives information on student data. This adjustment characterizes the new observations made on the student.

\section{EXPERIMENT AND RESULTS}

The functionality ROODAafeto, that congregates the frameworks AWM and BFC, was the resource which made it possible to collect data. The construction of the first framework was based on the Orengo [29] and Pasqualotti [30] works, while the model used in the second was based on Bercht model [22]. Information about the personality traits were obtained through the questionnaires of IFP [25] and self-evaluation from REA of eight students of two disciplines of the undergraduate program in Pedagogy from UFRGS (here we are presenting de first results).

The disciplines were taught in the face-to-face mode and the ROODA VLE served as support for the discussions outside the classroom. The communication functionalities used were the Forum and the Logbook. The case study students (4 male and 4 female) agreed to participate in our study voluntarily. Data collection was carried out along the first half of 2010. However, in this study, data concerning the first six weeks of the course is presented. During that time we recorded most of the contributions in the ROODA VLE.

Table 1 shows the results produced by the first part of the BN, whose topology is illustrated in Fig. 3. Probabilities highlighted inform the belief about the prevalence of personality traits. Table 2 presents the results obtained by the AWM framework used to identify the emotional subjectivity in messages posted in the communication functionalities. The AWM framework defines the quadrant, sub quadrant and the intensity of the affective state. In Table 2, the quadrants recognized (Int - Interested, Sat Satisfied, Und - Undefined) are presented. It is possible to observe in this table that students 192 and 561 did not show texts with affective connotation and 756 and 950 were the ones that exposed their subjectivity the most in the messages posted. 

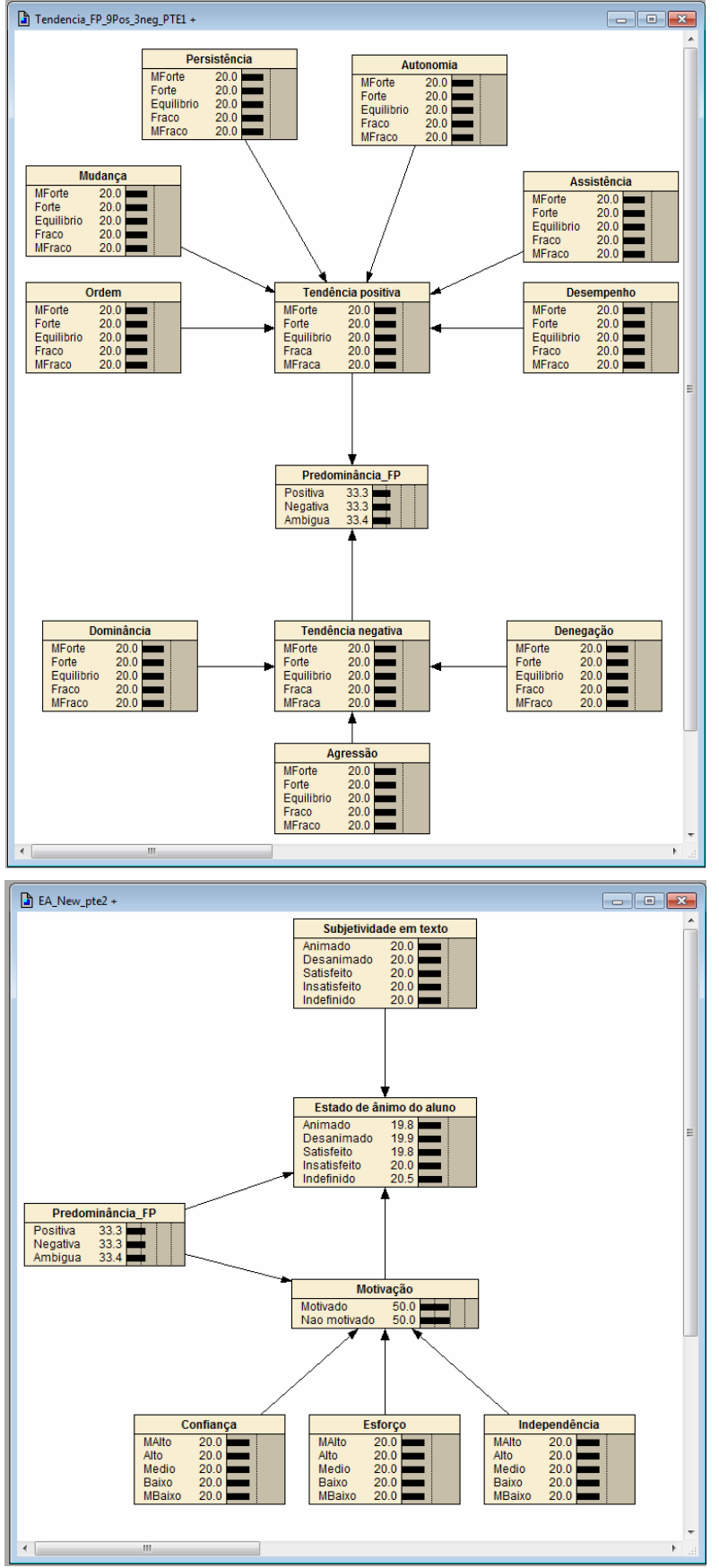

Figure 3. Bayesian Network of the study with the a priori CPT

Table 3 shows the results obtained by the inference machine based on the $\mathrm{BN}$ technique to generate estimate of occurrence of the mood states. Based on the degrees of the motivational factors Confidence, Effort and Independence, informed by the framework BFC, it was possible to verify the student's level of motivation in the six weeks of study. The level of motivation is presented in columns M (Motivated) and NM (Not Motivated).

It is observed in Table 3 that the values obtained for the students 192 and 561 define a higher estimate for Undefined although both were moderately motivated. The 756 student, fairly discouraged due to the way he or she behaved in the environment, presents results consistent with what is expressed in Table 2. The personality traits of this student confirmed the negative trend regarding (Table 1).
TABLE I.

PREDOMinANCE OF THE PERSONALity TRAITS

\begin{tabular}{|c|c|c|c|}
\hline \multirow{2}{*}{ Student } & \multicolumn{3}{|c|}{ Predominance } \\
\cline { 2 - 4 } & Positive & Negative & Ambiguous \\
\hline 109 & 0,097 & $\mathbf{0 , 5 4 7}$ & 0,356 \\
\hline 192 & $\mathbf{0 , 4 7 1}$ & 0,163 & 0,366 \\
\hline 309 & 0,216 & $\mathbf{0 , 4 1 9}$ & 0,365 \\
\hline 441 & 0,424 & $\mathbf{0 , 4 2 6}$ & 0,150 \\
\hline 561 & 0,233 & 0,209 & $\mathbf{0 , 5 5 8}$ \\
\hline 729 & $\mathbf{0 , 7 3 9}$ & 0,074 & 0,187 \\
\hline 756 & 0,116 & $\mathbf{0 , 7 6 2}$ & 0,122 \\
\hline 950 & 0,123 & 0,318 & $\mathbf{0 , 5 5 9}$ \\
\hline
\end{tabular}

TABLE II.

MOOD STATES OBTAINED THOUGH THE FRAMEWORK AWM

\begin{tabular}{|c|c|c|c|c|c|c|}
\hline \multirow{2}{*}{ Student } & \multicolumn{7}{|c|}{ Week } \\
\cline { 2 - 7 } & $\mathbf{1}$ & $\mathbf{2}$ & $\mathbf{3}$ & $\mathbf{4}$ & $\mathbf{5}$ & $\mathbf{6}$ \\
\hline 109 & Und & Und & Und & Int & Sat & Und \\
\hline 192 & Und & Und & Und & Und & Und & Und \\
\hline 309 & Und & Und & Und & Int & Sat & Und \\
\hline 441 & Und & Und & Und & Und & Int & Und \\
\hline 561 & Und & Und & Und & Und & Und & Und \\
\hline 729 & Und & Int & Und & Und & Int & Und \\
\hline 756 & Und & Int & Int & Int & Sat & Und \\
\hline 950 & Und & Sat & Sat & Und & Int & Und \\
\hline
\end{tabular}

TABLE III.

RESULTS OF THE INFERENCE MACHINE

\begin{tabular}{|c|c|c|c|c|c|c|c|}
\hline \multirow{2}{*}{ Student } & \multicolumn{2}{|c|}{ Motivation } & \multicolumn{6}{|c|}{ Mood States } \\
\cline { 2 - 8 } & $\mathbf{M}$ & $\mathbf{N M}$ & Int & Uni & Sat & Dis & Und \\
\hline 109 & $\mathbf{0 , 5 2}$ & 0,48 & 0,18 & 0,03 & $\mathbf{0 , 5 2}$ & 0,05 & 0,22 \\
\hline 192 & $\mathbf{0 , 6 5}$ & 0,35 & 0,19 & 0,13 & 0,18 & 0,13 & $\mathbf{0 , 3 7}$ \\
\hline 309 & $\mathbf{0 , 5 6}$ & 0,44 & $\mathbf{0 , 5 9}$ & 0,03 & 0,19 & 0,03 & 0,18 \\
\hline 441 & $\mathbf{0 , 6 0}$ & 0,40 & $\mathbf{0 , 6 4}$ & 0,03 & 0,17 & 0,03 & 0,15 \\
\hline 561 & $\mathbf{0 , 5 5}$ & 0,45 & 0,18 & 0,14 & 0,16 & 0,13 & $\mathbf{0 , 3 9}$ \\
\hline 729 & $\mathbf{0 , 7 2}$ & 0,28 & $\mathbf{0 , 7 8}$ & 0,02 & 0,12 & 0,02 & 0,06 \\
\hline 756 & 0,40 & $\mathbf{0 , 6 0}$ & $\mathbf{0 , 4 6}$ & 0,04 & 0,21 & 0,04 & 0,25 \\
\hline 950 & 0,47 & $\mathbf{0 , 5 3}$ & 0,16 & 0,03 & $\mathbf{0 , 5 8}$ & 0,04 & 0,19 \\
\hline
\end{tabular}

However, this student demonstrates a personality trait known as social desirability (SD) [25], as seen in his/her questionnaire IFP. SD in the IFP indicates the tendency of the research participant to present responses considered more acceptable, in short, that they are for social approval. The participants tend to conceal their opinions or their behavior, considering them socially undesirable. This may explain why the inference machine decided by the mood state that is "more favorable" to learning in relation to the poorly motivated student (relative to peers).

The 950 student shows a behavior similar to the 756, but with low SD. It can be concluded, therefore, the student showed to be really enthusiastic about the discipline. For the other students, the inference machine showed results similar to those expected. 


\section{VIII.FINAL CONSIDERATIONS}

The recognition of the affective states involves the capture and analysis of signals, which can be transformed into data for the construction of the user's affective model. Through it, the computer system can infer the reasons why the user has experienced a certain affective episode. For this purpose, it is necessary to construct and dynamically update the user's affective-cognitive model, contemplating the uncertainties of the data obtained in the recognition and the influence of the cognitive on the affective and vice versa.

The dynamic approach requires: a) the uncertainties arising from the type of model to be used to represent affectivity (Scherer's model), and b) possible failure to understand the variables used, given the probable instability of the "signs" captured. The use of probability reasoning implemented through BN is then started.

This study presents state of the art on the process of construction of an inference machine of the student's mood state in VLE. The machine (and the frameworks associated) inserted in the functionality ROODAafeto are being tested in the ROODA development environment.

In order to evaluate the possibility of construction, an experiment, whose data was submitted to a network prototype implemented though the software NETICA was conducted. In the simulation, the student counts on a cognitive and affective representation limited to the characteristics indispensible to the initial purposes of the research. This model aims to formalize their inter-relationships, either with the system or with colleagues. And even with the teachers and/or tutors. There is the prospect of developing two new studies. The first one, related to the incorporation of new features to the student's affective model, such as the learning style, according to Felder and Silverman [31] and the social attitude, identified through sociometric studies [32]. The second path to be taken refers to the inclusion of new variables in the calculation of motivational factors. Currently, only the variables associated with the communication tools of the ROODA VLE are considered in the calculation of behavioral patterns.

The objective of the research is to construct an adaptive computing system, that is, sufficiently dynamics and flexible in face of the characteristics of each student. From this, eventually, a new posture in relation to the interactions that are formed in the environment might result. Anyway, it is important to recognize that the teaching activity, mainly in a virtual environment, is a complex process. As such, aware of different potentialities, it is important to discuss if the difficulties found originate in technological or pedagogical deficiencies, or still, if they result from other reasons such those of individual nature.

\section{ACKNOWLEDGMENT}

The authors acknowledge the assistance of the psychologist Daniela Forgiarini Oliveira. She was responsible by application and analysis of IFP instrument on the participants of the case study.

\section{REFERENCES}

[1] Behar, P. A. Modelos Pedagógicos em Educação a Distância. Porto Alegre, RS, Brazil: Artmed. 2009.

[2] Picard, R. W. Affective Computing. Cambridge: MIT Press. 1997.

[3] Bercht, M. "Computação Afetiva: vínculos com a psicologia e aplicações na educação”, in Psicologia \& Informática: produções do III PsicoInfo e II Jornada do NPDI. São Paulo, SP, Brazil: Conselho Regional de Psicologia de São Paulo. p.106-115. 2007.

[4] Piaget, J. Inteligencia y Afectividad. Buenos Aires: Aique. Publicação original: Piaget, J. (1954). "Les relations entre l'Intelligence et l’Affectivité dans le développement de l'enfant”. 2005.

[5] Vygotski, L. S. A Construção do Pensamento e da Linguagem. São Paulo, SP, Brazil: Martins Fontes, 2001.

[6] Zajonc, R. B. "Feeling and thinking: preferences need no inferences”. American Psychologist, v.35, n.2, p. 151-175, Feb. 1980. http://dx.doi.org/10.1037/0003-066X.35.2.151

[7] Lazarus, R. S. "Thoughts on the relations between emotion and cognition”. American Psychologist, v.37, n.9, p. 1019-1010, Sep. 1982. http://dx.doi.org/10.1037/0003-066X.37.9.1019

[8] Damásio, A. O Erro de Descartes: emoção, razão e o cérebro humano. São Paulo, SP, Brazil: Cia das Letras. 1996.

[9] Le Doux, J. O Cérebro Emocional: os Misteriosos Alicerces da Vida Emocional. Rio de Janeiro, RJ, Brazil: Objetiva. 2001.

[10] Scherer, K. R."What are emotions? And how can they be measured?”. Social Science Information v. 44, n.4, p. 695-729. 2005. http://dx.doi.org/10.1177/0539018405058216

[11] Ekman, P. "Basic Emotions”, in Dalgleish, T. \& Power, T. (Eds.). The Handbook of Cognition and Emotion. Sussex, U.K.: John Wiley \& Sons, Ltd. p. 45-60. 1999

[12] Rosenberg, E.L. "Levels of analysis and the organization of affect”. Review of General Psychology, v. 2, n. 3, p. 247-270. 1998. http://dx.doi.org/10.1037/1089-2680.2.3.247

[13] Fellous J. M., Armony J. L., and Le Doux J. E. "Emotional Circuits and Computational Neuroscience", in A ib, M.A. (Ed.), The handbook of brain theory and neural networks, Second Edition. Cambridge, MA: The MIT Press. 2002

[14] Gratch, J., and Marsella, S. “A Domain-independent framework for modeling emotion”. Journal of Cognitive Systems Research, v.5, n.4, p. 269-306. 2004. http://dx.doi.org/10.1016/j.cogsys. 2004.02.002

[15] Ball, G., and Breese, J. "Relating personality and behavior: posture and gestures”, in Paiva, A. M. (Ed.): Affective Interactions, LNAI 1814, 2000. http://dx.doi.org/10.1007/10720296_14

[16] Kshirsagar, S., and Magnenat-Thalmann, N. A Multilayer Personality Model, New York: ACM Press, p.107-115. 2002. [2nd International Symposium on Smart Graphics, June 11-13, 2002, Hawthorne, NY, USA]. http://dx.doi.org/10.1145/569005.569021

[17] Conati, C., and Maclaren, H. "Empirically building and evaluating a probabilistic model of user affect”. User Modeling and UserAdapted Interaction, v.19, n.3, p. 267-303. 2009. http://dx.doi.org/10.1007/s11257-009-9062-8

[18] Pantarolo, E. Modelagem probabilística de aspectos afetivos do aluno em um jogo educacional colaborativo. Porto Alegre, RS, Brazil: PPGIE/UFRGS. 2008.

[19] Boff, E. Colaboração em ambientes inteligentes de aprendizagem mediada por um agente social probabilístico. Porto Alegre, RS, Brazil: PGCC/UFRGS. 2008.

[20] Dorsch, F., Häcker, H., and Stapf, K. H. Dicionário de Psicologia Dorsch. Petrópolis, RJ, Brazil: Vozes. 2008.

[21] Longhi, M. T., Behar, P. A., and Bercht, M. "Em busca de palavras com conotação afetiva registradas em ambiente virtual de aprendizagem". Conferência IADIS Ibero-Americana WWW/Internet 2010, Algarve. Portugal. p. 43-50. 2010.

[22] Bercht, M. "Em direção a agentes pedagógicos com dimensões afetivas”. Porto Alegre, RS, Brazil: PGCC/UFRGS, 2001.

[23] Del SOLDATO, T.; Du BOULAY, B. "Implementation of motivational tactics in tutoring systems”. Journal of Artificial Intelligence in Education, v. 6, n. 4, p. 337-378. 1995

[24] Longhi, M. T., Behar, P. A., Bercht, M. and Simonato, G. “Os fatores motivacionais e os estados de ânimo em ambientes virtuais de aprendizagem”. Congresso Iberoamericano de Informática Educativa. Santiago do Chile, Chile, Dez. 1-3, 2010. p. 551-558. 2010.

[25] Pasquali, L., Azevedo, M. M., and Ghesti, I. Inventário Fatorial de Personalidade: Manual técnico e de aplicação. São Paulo, SP, Brazil: Casa do Psicólogo. 1997. 
[26] Scherer, K. R., and Tran, V. "Effects of emotion on the process of Organization Learning", in Nonaka I. (Ed.). Handbook of organizational learning and knowledge. Oxford, UK: Oxford University Press. p. 369-392. 2001

[27] Tran, V. The influence of emotions on decision-making processes in management teams. Faculte de Psychologie et des Sciences de l'Education. Université de Genève. Thèse No 323. 2004.

[28] Russell, S.J., and Norving, P. Inteligência Artificial. Rio de Janeiro: Elsevier. 2004.

[29] Orengo, V. M., Buriol, L. S., and Coelho, A. R. "A Study on the Use of Stemming for Monolingual Ad-Hoc Portuguese Information Retrieval”, in Peters, C. et al. (Eds.). Evaluation of Multilingual and Multi-modal Information Retrieval. CLEF 2006, LNCS 4730, pp. 91-98. 2007.

[30] Pasqualotti, P. R. "Reconhecimento de expressões de emoções na interação mediada por computador”, São Leopoldo, RS, Brazil: PPCA/UNISINOS, 2008.

[31] Felder, R., and Silverman, L. K. "Learning styles and teaching styles in Engineering education”. Engineering Education. v.78, n.7, p. 674-681. 1998

[32] Scherman, L. W. Sociometry in the classroom: how to do it. $<$ http://www.users.muohio.edu/shermalw/sociometryfiles/socio in troduction.htmlx >. 2002.

\section{AUTHORS}

Magalí T. Longhi is PhD student in Computer Science applied to Education Program (PGIE) at the Inter- disciplinary Center of New Technologies in Education (CINTED) at the Federal University of Rio Grande do Sul (UFRGS), Brazil. She is working on affective computing on virtual learning environments. (e-mail: magali@cpd.ufrgs.br)

Patricia Alejandra Behar, is professor at the Education School and at the Post Graduation Programs in Education (PGEdu) and Computer Science applied to Education (PGIE) at the Federal University of Rio Grande do Sul (UFRGS). She is coordinator of the Digital Technology Nucleus in Education (NUTED). (e-mail: pbehar@terra.com.br).

Magda Bercht is associated professor at the Post Graduation Programs in Computer Science (PGCC) and Computer Science applied to Education Program (PGIE) at the Federal University of Rio Grande do Sul (UFRGS). She has been dedicated to affective computing, intelligent tutoring systems, and multiagents systems. (e-mail: bercht@inf.ufrgs.br).

This work was supported in part by the Brazilian National Council for Scientific and Technological Development (CNPq) and Rio Grande do Sul Research Foundation (FAPERGS). Received 4 July 2011. Published as resubmitted by the authors 27 February 2012. 